\title{
Could hantavirus circulation superpose areas of highly endemic vaccinia virus outbreaks? A retrospective seroepidemiological study in State of Minas Gerais
}

\author{
Giliane de Souza Trindade ${ }^{[1]}$, André Tavares da Silva Fernandes ${ }^{[2]}$, Galileu Barbosa Costa ${ }^{[1]}$, \\ Poliana de Oliveira Figueiredo[1], Jônatas Santos Abrahão[1], Erna Geessien Kroon ${ }^{[1]}$, \\ Luiz Tadeu Moraes Figueiredo ${ }^{[3]}$ and Flávio Guimarães da Fonseca ${ }^{[4]}$
}

[1]. Laboratório de Vírus, Instituto de Ciências Biológicas, Departamento de Microbiologia, Universidade Federal de Minas Gerais, Belo Horizonte, MG. [2]. Instituto de Tecnologia em Imunobiológicos, Fundação Oswaldo Cruz, Rio de Janeiro, RJ. [3]. Centro de Pesquisa em Virologia, Faculdade de Medicina de Ribeirão Preto, Universidade de São Paulo, Ribeirão Preto, SP. [4]. Laboratório de Virologia Básica e Aplicada, Instituto de Ciências Biológicas, Departamento de Microbiologia, Universidade Federal de Minas Gerais, Belo Horizonte, MG.

\begin{abstract}
Introduction: Hantavirus infections have been described in several regions in Brazil through seroepidemiological studies. Usually, populations are associated with rural and wild environment mainly due to close contact to species of Sigmodontinae rodents, considered hantavirus reservoirs. Methods: A retrospective serosurvey was conducted to access the hantavirus seroprevalence in people living in regions affected by bovine vaccinia outbreaks. Results: Sera from 53 patients were analyzed and none of them presented anti-hantavirus IgG antibodies. Conclusions: This study presents an opportunity to analyze seronegativity despite close and recurrent contact with known hantavirus reservoirs. Aspects of hantavirus and bovine vaccinia emergence are also discussed.
\end{abstract}

Keywords: Hantavirus. Rural population. Bovine vaccinia.

In South America, species of the Hantavirus genus (Bunyaviridae family) are associated with a spectrum of clinical symptoms varying from asymptomatic or oligosymptomatic presentations to hantavirus pulmonary syndrome (HPS) ${ }^{1}$. In Brazil, the first cases of hantavirus infection were described in 1993 in State of São Paulo, and more than 1,500 confirmed cases have been described since ${ }^{1,2}$. Cases of hantaviruses in Minas Gerais State have been described since 1998, and the Southeastern region of the state accumulates most of the cases ${ }^{3,4}$. Several serological studies conducted in the country have presented evidence of hantavirus circulation in different human populations in the absence of reported HPS ${ }^{2,4-9}$. This suggests the possibility of silent virus transmission and consequently an underestimation of the virus's spatial distribution.

Hantavirus disease is a zoonotic infection transmitted from infected rodent reservoirs to humans by direct contact (i.e., a bite) or inhalation of infectious aerosols produced from the rodents' excreta ${ }^{1}$. In Brazil, very little is known about the role

Address to: Dra. Giliane de Souza Trindade. Laboratório de Vírus/ICB/Depto. de Microbiologia/UFMG. Av. Presidente Antônio Carlos 6627, Pampulha, 31270-901 Belo Horizonte, MG, Brasil.

Phone: 5531 3409-2747; Fax: 5531 3443-6482

e-mail: giliane@icb.ufmg.br

Received 13 February 2014

Accepted 26 June 2014 of rodent species in the transmission of several potential rodentborne emerging pathogens, except for hantavirus, whose host ecology has been successfully investigated in previous years ${ }^{1}$. Several species of Sigmodontinae rodents, especially of the Calomys, Necromys, Akodon, Rhipidomys, and Oligoryzomys genera, are considered reservoirs of hantaviruses ${ }^{1}$. Some of the rodent genera associated with hantavirus transmission circulate in areas where other zoonotic virus infections such as bovine vaccinia (BV), caused by Vaccinia virus (VACV, Orthopoxvirus genus, Poxviridae family), have been described ${ }^{10,11}$. Interestingly, hantavirus and VACV share a similar pattern of emergence, with cases being reported mainly in areas with highly disturbed ecosystems where overlapping of urban, agricultural, and cattleraising areas occurs ${ }^{5,12}$.

For the past twelve years, cases of exanthematic infections caused by VACV have been described in rural areas of Brazil. $\mathrm{BV}$ affects dairy herds and people who have direct contact with lesions on the animals, mainly milkers and farmers ${ }^{10,13}$. So far, clinical cases have been reported in all regions of Brazil, although most cases are concentrated the Southeast, affecting mainly unsophisticated rural properties in which the milking process is still done manually ${ }^{10-13}$. Minas Gerais is the most affected state, with reported cases in all subregions because of the large concentration of dairy farms. Our research team has been actively involved in several studies regarding the emergence of BV in Brazil as well as VACV ecology ${ }^{10,11}$.

The host transmission chain of VACV in Brazil is still poorly understood, but recent findings have shown the participation 
of synanthropic and wild rodents in the natural transmission cycle of the virus ${ }^{10,11}$. Based on the fact that in Minas Gerais cases of BV and hantavirus have been observed in overlapping geographical areas and that the viruses can infect several common rodent hosts ${ }^{14}$, we decided to investigate whether a population exposed to VACV at different locations in State of Minas Gerais has also been exposed to hantavirus without developing classical clinical symptoms of HPS or other clinical forms associated with the infection.

The study protocol was conducted according to the Brazilian National Council of Health regulations and was approved by the Instituto René Rachou Review Board under protocol number 03/2006. All patients were participants in a BV cross-sectional study conducted by our team in 2005 and 2006 from several regions of State of Minas Gerais. After signing informed consent forms, the participants agreed to be interviewed and had blood samples collected. A total of 53 men and women showing signs of poxvirus infection and residing in seven municipalities in Minas Gerais with ages ranging from 18 to 70 years were enrolled in this study (Figure 1 and Figure 2). Laboratory analyses with previously described methodologies confirmed poxvirus infection ${ }^{10}$. Most patients were either farmers or milkers, and one was a housewife. Sera samples were tested by immunoglobulin $\mathrm{G}$ ( $\mathrm{IgG}$ )-enzyme-linked immunosorbent assay using a recombinant nucleocapsid protein from Araraquara virus, a Brazilian hantavirus strain, as the antigen ${ }^{15}$. Samples were tested in duplicate, and a known Araraquara-positive sample was used as a positive control. A protein extract not containing recombinant protein was used as a negative control ${ }^{15}$.

Our results show that none of the 53 samples tested were positive for hantavirus IgG antibodies. There have been several independent studies describing BV or hantavirus outbreaks in Brazil. Clearly, these investigations show eco-geographic and occupational similarities between outbreaks caused by the two viruses $^{10-12}$. In general, cases of BV or hantavirus infections have been described in rural areas where the natural environment has been disturbed, creating a mosaic of deforested areas, pastures, agricultural fields, and human dwellings. Also, as observed for $\mathrm{BV}$, hantavirus infection seems to be an occupational disease, and some areas of the country are strongly associated with rural labor activities ${ }^{5,12}$. However, in this study there was no positive correlation between exposure of the analyzed population to VACV (all patients were positive for BV infection) and hantavirus.

In spite of the fact that the population analyzed here lives in geographical areas where hantaviruses are known to circulate (Figure 1 and Figure 2) or live in areas where the same VACV and hantavirus rodent hosts circulate, there is some sample bias that should be considered in order to discuss the findings. This is a retrospective study, and the choice of the population occurred in the context of BV outbreaks. Thus, when samples were obtained there was no specific objective to seek a population with clinical indications of previous hantavirus infection. In fact, patients were enrolled only when they presented indications of either previous or ongoing poxvirus infection. Indeed, other studies have demonstrated the low seroprevalence of hantavirus in different populations ${ }^{2,4-9}$, which is not so different from what we have seen in our analyses. Considering that the size of the analyzed population is relatively small, comprising only 53 patients, the odds of randomly finding hantavirus-seropositive patients may be slight. However, an obvious connection among men, cattle, and rodents has been established in the context of $\mathrm{BV}$, although the exact mechanism by which the circulating VACV reaches hosts is not clear. Nevertheless, we know that humans and cattle are not VACV reservoirs, leaving only rodents to blame. Thus, if rodents are putative reservoirs for VACV and known reservoirs for hantaviruses, it is plausible that of VACV and hantavirus co-circulate in the same region, especially taking into account that the rodent species that harbor hantaviruses inhabit in the same areas where BV has occurred (Figure 1 and Figure 2).

Most patients enrolled in this study were males, and a majority were milkers. Despite the fact that several visited farms and had barns and facilities to store grain nearby the corrals and dwellings and that all patients reported seeing rodents frequently, the rural labor activities conducted by the studied individuals could be different from patients usually affected by hantavirus infections. On the other hand, as demonstrated by Limongi and colleagues, exposure factors involving rodents are not necessarily related to the presence of anti-hantavirus antibodies ${ }^{4}$.

One interesting aspect to consider is that several serological and hantavirus outbreak investigations have suggested that the act of sweeping around houses or barns, which generates large amounts of aerosol particulates, predisposes individuals to infection. This is primarily an activity conducted by women on Brazilian farms, and only one woman with domestic and milking activities was enrolled in the study. This may be an important bias as well.

Finally, patients in this study were mostly responsible for activities associated with cattle management, especially milking. Such activities are usually not related to planting and harvesting, camping, or hunting, which are known risk factors for acquiring Hantavirus infections ${ }^{7-9}$.

Species in the hantavirus subfamily Sigmodontinae are abundant in the Atlantic Forest area, and they present a considerable capacity for adaptation to human-dominated environments, including plantations and forestry areas. However, based on the fact that hantavirus prevalence could respond to changes in levels of biodiversity, species diversity can help decrease prevalence by diluting the availability of competent hosts with increased numbers of less competent hosts. Also, it is important to emphasize that predators' actions can control rodent populations and therefore are important in controlling pathogen transmission.

Given the fact that in the State of Minas Gerais BV infection occurs in areas with overlapping geographical risks for acquiring hantavirus infection and vice versa, our findings cannot rule out the possibility of co-circulation of both viruses in the same rodent populations. However, our results do suggest an important occupational separation in terms of risk assessments for each viral infection. 


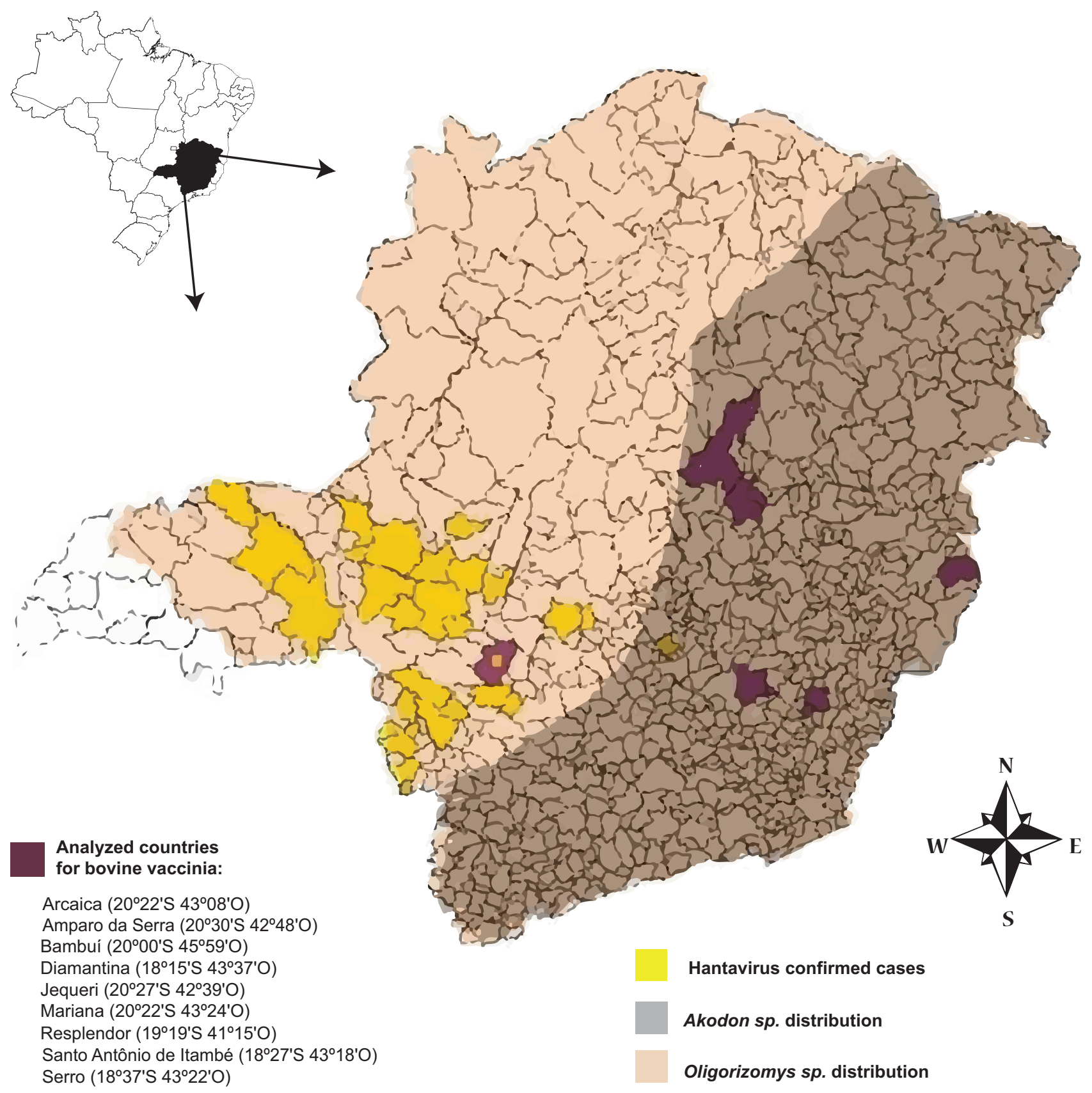

FIGURE 1 - Distribution of hantavirus reservoirs (Oligorizomys sp. and Akodon sp.) in State of Minas Gerais. Areas with hantavirus confirmed cases and bovine vaccinia occurrence are also highlighted. 

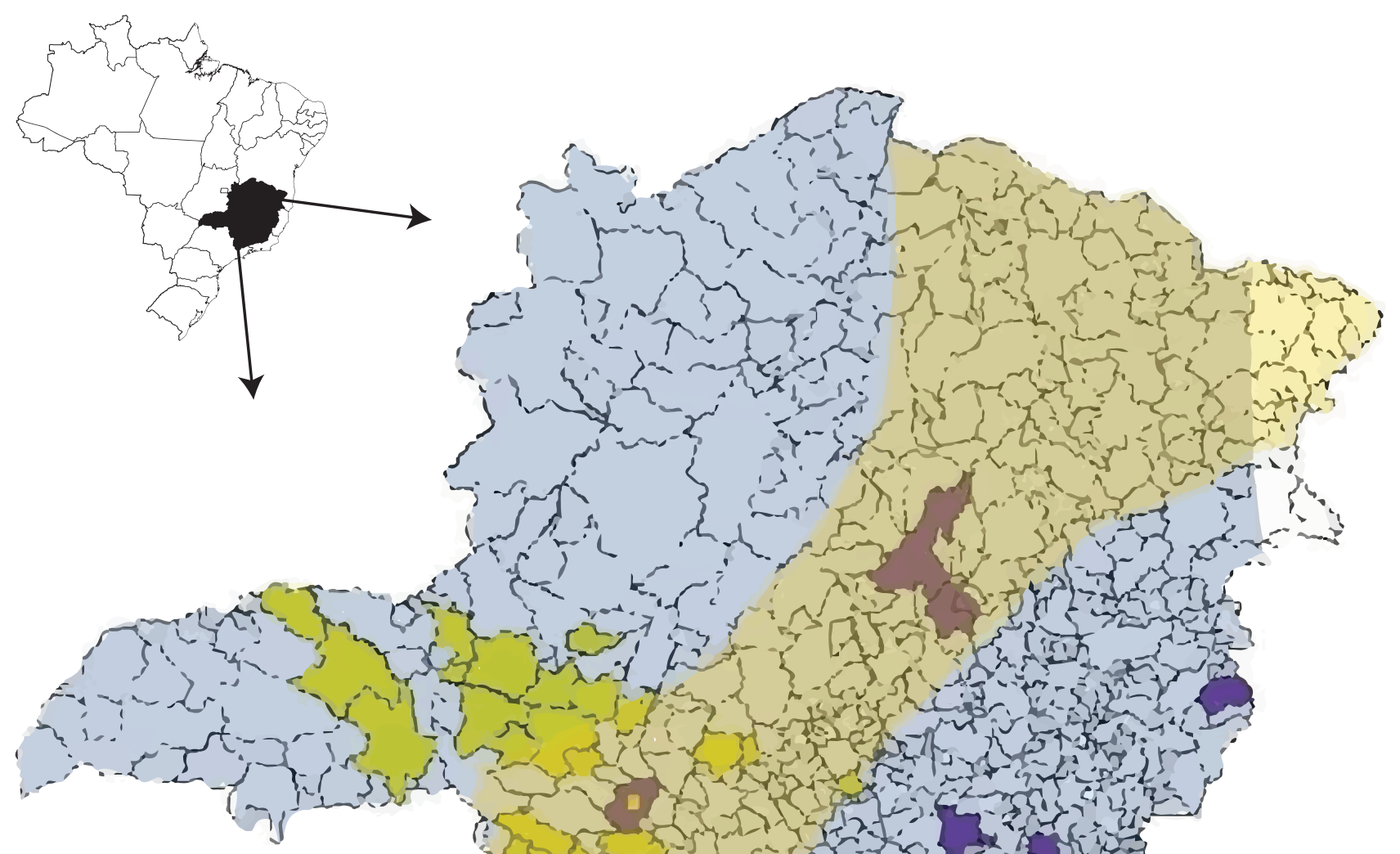

Analyzed countries for bovine vaccinia:

Arcaica $\left(20^{\circ} 22^{\prime} \mathrm{S} 43^{\circ} 08^{\prime} \mathrm{O}\right)$

Amparo da Serra $\left(20^{\circ} 30^{\prime} \mathrm{S} 42^{\circ} 48^{\prime} \mathrm{O}\right)$

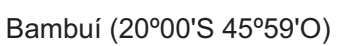

Diamantina $\left(18^{\circ} 15^{\prime} \mathrm{S} 43^{\circ} 37^{\prime} \mathrm{O}\right)$

Jequeri $\left(20^{\circ} 27^{\prime} \mathrm{S} 42^{\circ} 39^{\prime} \mathrm{O}\right)$

Mariana $\left(20^{\circ} 22^{\prime} \mathrm{S} 43^{\circ} 24^{\prime} \mathrm{O}\right)$

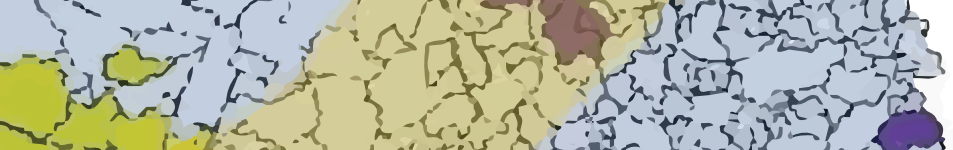

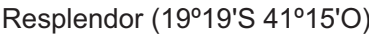

Santo Antônio de Itambé $\left(18^{\circ} 27^{\prime} \mathrm{S} 43^{\circ} 18^{\prime} \mathrm{O}\right)$

Serro $\left(18^{\circ} 37^{\prime} \mathrm{S} 43^{\circ} 22^{\prime} \mathrm{O}\right)$

FIGURE 2 - Distribution of hantavirus reservoirs (Necromys sp. and Cerradomys sp.) in State of Minas Gerais. Areas with hantavirus confirmed cases and bovine vaccinia occurrence are also highlighted. 
This and previous research has established that the epidemiology of hantavirus and BV infection is dependent on direct exposure to rodents and the population dynamics of the reservoir species. Additional studies focusing on ecologic and epidemiologic variables of hantavirus infection are under development in the affected areas in order to clarify aspects of the dynamic circulation of hantaviruses in the rodent population.

\section{ACKNOWLEDGMENTS}

The authors would like to thank João Rodrigues dos Santos, Angela Sana Lopes, Ilda Gamma, and colleagues from Laboratório de Virus (Instituto de Ciências BiológicasUniversidade Federal de Minas Gerais) for their excellent technical support and Karim S Marins for editing the figures. The authors would also like to thank the Instituto Mineiro de Agropecuária (IMA) for technical support during the field expeditions.

\section{CONFLICT OF INTEREST}

The authors declare that there is no conflict of interest.

\section{FINANCIAL SUPPORT}

Financial support was provided by the Conselho Nacional de Desenvolvimento Científico e Tecnológico (CNPq), Coordenação de Aperfeiçoamento de Pessoal de Nível Superior, Fundação de Amparo à Pesquisa do Estado de Minas Gerais, Ministério da Agricultura, Pecuária e Abastecimento. G.S. Trindade, E.G. Kroon and F.G. da Fonseca are CNPq fellowship recipients.

\section{REFERENCES}

1. Jonsson CB, Figueiredo LTM, Vapalahti O. A global perspective on hantavirus ecology, epidemiology, and disease. Clin Microbiol Rev 2010; 23:412-441.

2. Badra SJ, Maia FGM, Figueiredo GG, Santos Júnior GS, Campos GM, Figueiredo LTM, et al. A retrospective serological survey of hantavírus infections in the county of Cássia dos Coqueiros, State of São Paulo, Brazil. Rev Soc Bras Med Trop 2012; 45:468-470.

3. Limongi JE, Costa FC, Paula MBC, Pinto RMC, Oliveira MLA, Pajuaba Neto AA, et al. Hantavirus cardiopulmonary syndrome in the Triângulo Mineiro and Alto Paranaíba regions, State of Minas Gerais, 1998-2005: clinical-epidemiological aspects of 23 cases. Rev Soc Bras Med Trop 2007; 40:295-299.

4. Limongi JE, Costa FC, Pinto RMC, Oliveira RC, Bragagnolo C, Lemos ERS, et al. Cross-sectional survey of hantavirus infection, Brazil. Emerg Infec Dis 2009; 15:1981-1983.

5. Medeiros DBA, Rosa EST, Marques AAR, Smith DB, Carneiro AR, Chiang JO, et al. Circulation of hantaviruses in the influence area of the Cuiabá-Santarém Highway. Mem Inst Oswaldo Cruz 2010; 105:665-671.

6. Lima DM, Santos Júnior GS, Oliveira ACA, Fontes RM, Colares JKB, Araújo FMC, et al. Hantavirus infection in suspected dengue cases from State of Ceará, Brazil. Rev Soc Bras Med Trop 2011; 44:795796.

7. Souza WM, Machado AM, Disner GR, Boff E, Machado ARSR, Paula $\mathrm{M}$, et al. Antibody levels to hantavirus in inhabitants of western Santa Catarina State, Brazil. Rev Inst Med Trop Sao Paulo 2012; 54:193-196.

8. Gimaque JBL, Bastos MS, Braga WSM, Oliveira CMC, Castilho MC, Figueiredo RMP, et al. Serological evidence of hantavírus infection in a rural and urban regions in the State of Amazonas, Brazil. Mem Inst Oswaldo Cruz 2012; 107:135-137.

9. Pereira GW, Teixeira AM, Souza MS, Braga AD, Santos Júnior GS, Figueiredo GG. Prevalence of serum antibodies to hantavirus in a rural population from the Southern of Santa Catarina, Brazil. Rev Soc Bras Med Trop 2012; 45:117-119.

10. Kroon EG, Mota BE, Abrahão JS, Fonseca FG, Souza Trindade G. Zoonotic Brazilian Vaccínia vírus: from field to therapy. Antiviral Res 2011; 92:150-163.

11. Abrahão JS, Guedes MI, Trindade GS, Fonseca FG, Campos RK, Mota BF, et al. One more piece in the VACV ecological puzzle: could peridomestic rodents be the link between wildlife and bovine vaccinia outbreaks in Brazil? PLoS One 2009; 4:e7428.

12. Schatzmayr HG, Costa RV, Gonçalves MC, D' Andréa PS, Barth OM. Human and animal infections by vaccinia-like viruses in the state of Rio de Janeiro: A novel expanding zoonosis. Vaccine 2011; 29 : 65-69.

13. Medaglia MLG, Pessoa LCGD, Sales ERC, Freitas TRP, Damaso CR. Spread of Cantagalo virus to northern Brazil. Emerg Infect Dis 2009; 15:1142-1143.

14. Peres MG, Bacchiega TS, Appolinário CM, Vicente AF, Allendorf SD, Antunes JMAP, et al. Serological study of Vaccinia virus reservoirs in areas with and without official reports of outbreaks in cattle and humans in São Paulo, Brazil. Arch Virol 2013; 158:2433-2441.

15. Figueiredo LTM, Moreli ML, Borges AA, Figueiredo GG, Badra SJ, Bisordi I, et al. Evaluation of an enzyme-linked immunosorbent assay based on Araraquara virus recombinant nucleocapsid protein. Am J Trop Med Hyg 2009; 81:273-276. 